\title{
Reasons for dropout in swimmers, differences between gender and age and intentions to return to competition
}

\author{
Diogo M. MONTEIRO 1, 2 *, Daniel A. MARINHO 2,3, João M. MOUTÃO 1,2, \\ Anabela P. VITORINO 1, Raúl N. ANTUNES 1, Luís S. CID 1,2
}

${ }^{1}$ Sport Science School of Rio Maior, ESDRM-IPSANTAREM, Rio Maior, Portugal; ${ }^{2}$ Research Center in Sports, Health and Human Development, CIDESD, Portugal; ${ }^{3}$ Unversity of Beira Interior, Department of Sport Sciences, Covilhã, Portugal

*Corresponding author: Diogo M. Monteiro, Research Center in Sports, Health and Human Development, Sport Science School of Rio Maior, Polytechnic Institute of Santarém, ESDRM- IPSantarém, Av. Dr. Mário Soares 2040-413, Rio Maior, Portugal. E-mail: diogomonteiro@esdrm.ipsantarem.pt

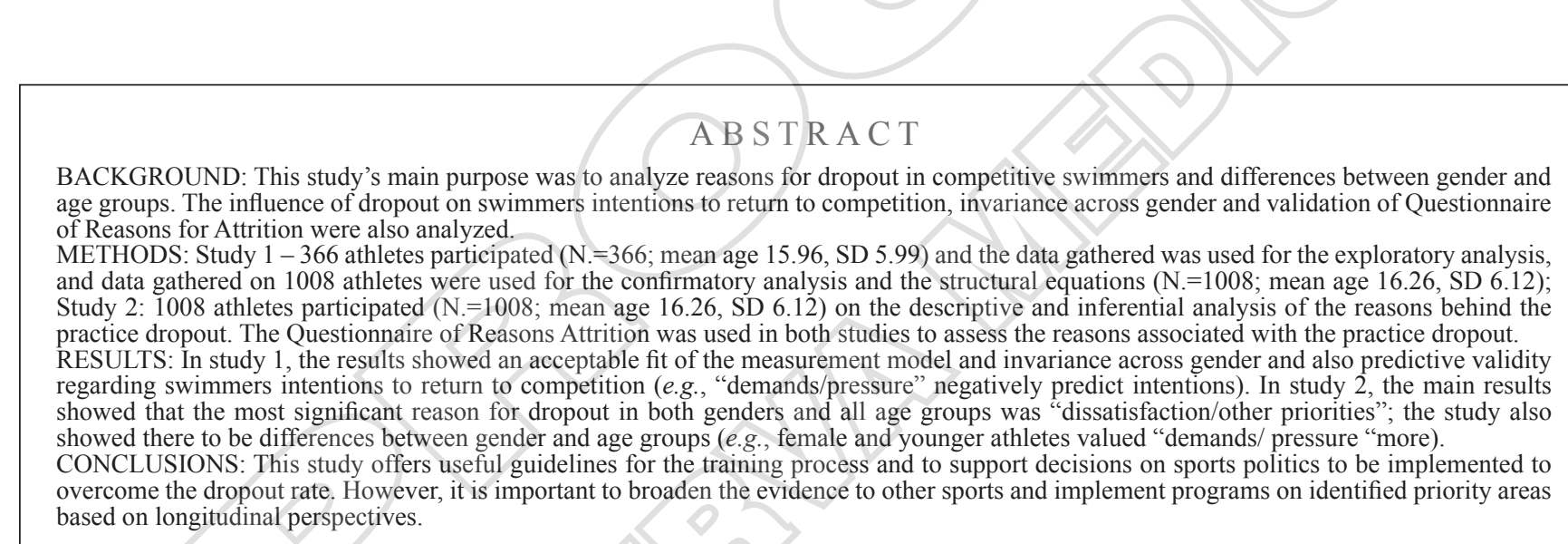

(Cite this article as: Monteiro DM, Marinho DA, Moutão JM, Vitorino AP, Antunes RN, Cid LS. Reasons for dropout in swimmers, differences between gender and age and intentions to return to competition. J Sports Med Phys Fitness 2017;57: . DOI: $10.23736 / \mathrm{S} 0022-4707.17 .06867-0)$

Key words: Swimming - Intention - Age groups.

$\mathrm{O}^{\mathrm{s}}$ ver the past decades, the study of dropping out of sports practice has aroused interest and concern by researchers. ${ }^{1-7}$ Consequently, these studies have become quite useful in understanding the dynamics of this phenomenon and have generated, complex theories (an integrative model by Gould). ${ }^{2}$ It seems the dropout phenomenon does not have a single cause but is due to a set of diversified reasons. ${ }^{2,8,9}$

On the other hand, a controversial question about the dropout phenomenon is its concept, as it has not been clarified in several studies, ${ }^{4,9}$ resulting several times in doubts as to whether we are looking at a specific or general sports practice dropout. ${ }^{2}$ For the present study, the conceptual framework that best suits the dropout is the definition presented by Cervelló: 10 the sports dropout can be considered in a general way, the situation where the individuals finalize their explicit commitment with a specific sport practice. From this definition, it is understandable why it is so important to study dropout in each sports practice, which is to say, so that the phenomenon can be more clearly understood ${ }^{1,7}$ and so that specific tools can be developed to prevent dropout. 
However, when it comes to literature analysis, it looks like dropout in sports is not that well studied, since from the 1970s until the new millennium only a few more than 30 studies regarding dropout have been published. ${ }^{4}$ Besides that, only one systematic review concerning dropout in organized sports has been published, ${ }^{11}$ reporting that from 1981 to 2011 only 43 studies were published on this topic and only five of those studies analyzed specifically the swimming context during this period. Intention is another variable that is associated with dropout and is appealing to researchers. 5,6 According to the literature, intentions represent the best variable to predicts future behavior. ${ }^{12}$ Although some studies have focused on analyzing the impact of motivation on still-active athletes' intention to dropout ${ }^{6}$ and others have focused on the athletes' intentions to continue to practice sports, ${ }^{5}$ it appears that there is no study that shows the impact of the dropout reasons on the athletes' intentions to return to the sport after dropping out.

In order to tackle to this issue, the present study has two objectives: with respect to study 1, translate and validate the QRA for the Portuguese sample, using an exploratory factor analysis (EFA) and confirmatory factor analysis (CFA) with independent samples. The first objective is also to analyze the measurement model invariance by gender, and to measure the impact of the reasons for dropout and intention to return to practice, using structural equation modelling (SEM); with respect to study 2 , the objective is to analyse the dropout reasons by gender and age groups.

\section{STUDY 1}

Having considered the systematic review of dropout, ${ }^{11}$ there are a few questionnaires that assess the reasons behind sports practice dropout. They include the Motives of Initiation, Maintenance, Change and Dropout questionnaire, ${ }^{13}$ Sports Career Termination, ${ }^{14}$ and Non-Athletic Transitions Questionnaire, ${ }^{14}$ which was used with still-active athletes and the Questionnaire of Reasons for Attrition in Swimming (QRA). ${ }^{3}$ This last questionnaire, composed of 32 items arranged on a 3 -point Likert Scale, assesses the reasons athletes gave for dropping out from sports practice. The QRA was developed specifically for the swimming context, which is why we opted to use it in the present study. It has been used for several studies not only in the swimming context ${ }^{3}$ but also with respect to other sports. ${ }^{15,16}$
Gould et al. ${ }^{3}$ developed the QRA, starting from the Participation Motives Questionnaire ${ }^{17}$ and with the intention of studying the dropout reasons of young swimmers by gender, age and sports history. The psychometric qualities of the original version of QRA were analyzed, however, no factorial structure was identified. The analysis of the principal components resulted in 10 factors which, in the author's opinion, were not sufficiently interpretable. ${ }^{3}$

Even with the indicated weak psychometrics, the QRA was translated and validated, for the Spanish language 18 through an exploratory factor analysis with a sample of 66 swimmers. In this validation study, the authors deleted items 23, 26 and 28, ending up with a structure of six factors and 29 items. However, the Spanish version has some psychometric weaknesses, namely an insufficient sample $(\mathrm{N} .=66)$ for this kind of analysis, since the original questionnaire has 32 items and a ratio of (10:1) with a minimum of $(5: 1)$ being recommended. ${ }^{19}$ In addition, the items do not have an suitable weight for the sample size, with a factorial weight of greater than or equal to 0.70 recommended for samples with 60-70 participants. ${ }^{19}$ The survey also has an inappropriate internal consistency ('factor influencia de otros' [others influence factor]) $=0.58$ ), with 0.60 as the minimum acceptable value, ${ }^{19}$ and a factor is retained with only two items, three being the minimum acceptable, so that it may reflect a latent factor. ${ }^{20}$

Recently, Rottenstein et al. ${ }^{16}$ focused on identifying the reasons for dropout among 527 Finnish athletes who were, practitioners of team sports. The study translated and validated for the Finnish language the original version of the QRA, ending up with a structure of 4 factors and 18 items that generally showed good validity and reliability.

Despite the fact that the QRA factorial structure shows some fragilities regarding psychometrics, which is common in questionnaires of this nature (those that assess reasons for dropout/practice), it is expected that the present study will help to fill the gap in the international literature, extending and spreading the evidence concerning dropout reasons.

\section{Materials and methods}

\section{Subjects}

The EFA included 366 former swimmers (200 male and 166 female; mean age 15.96, SD 5.99) of the Portu- 
guese Swimming Federation (FPN) who dropped out of competitive swimming practice during the 2012-2013 and 2013-2014 seasons and did not return. This sample comprised the following age groups: 60 cadets (males: age 8-12 years; females: 7-11 years), 64 children (males: age 13-14 years; females: 12-13 years), 81 juveniles (males: age 15-16 years; females: $14-15$ years), 71 juniors (males: age 17-18 years; females: 16-17 years) and 90 seniors (males: 19 years and older; females: 18 years and older), according to the FPN categories.

For the cadets the weekly training sessions varied between 2 and $6(\mathrm{M}=3.53 ; \mathrm{SD}=1.09)$; the number of hours per session varied between 1 and 3 hours $(M=1.63$; $\mathrm{SD}=0.55)$, corresponding to a weekly practice of approximately 6 hours.

For the children the weekly training sessions varied between 2 and $8(\mathrm{M}=4.18 ; \mathrm{SD}=1.49)$; the number of hours per session varied between 1 and 3 hours $(\mathrm{M}=2.03 ; \mathrm{SD}=0.61)$, corresponding to a weekly practice of approximately 8 hours.

For the juveniles, the weekly training sessions varied between 2 and $10(\mathrm{M}=5.21 ; \mathrm{SD}=1.58)$; the number of hours per session varied between 1 and 3 hours $(\mathrm{M}=2.01 ; \mathrm{SD}=0.51)$, corresponding to a weekly practice of approximately 10 hours.

For the juniors, the weekly training sessions varied between 2 and $11(\mathrm{M}=6.11 ; \mathrm{SD}=2.02)$; the number of hours per session varied between 1 and 3 hours $(\mathrm{M}=2.04 ; \mathrm{SD}=0.57)$, corresponding to a weekly practice of approximately 12 hours.

For the seniors, the weekly training sessions varied between 2 and $11(\mathrm{M}=6.04 ; \mathrm{SD}=1.72)$; the number of hours per session varied between 1 and 4 hours $(\mathrm{M}=2.00 ; \mathrm{SD}=0.60)$, corresponding to a weekly practice of approximately 12 hours.

The CFA and SEM included 1008 former swimmers (543 male, 465 female; mean age 16.26, SD 6.12) who dropped out of competitive swimming practice during the 2012-2013 and 2013-2014 seasons and did not return. This sample comprised the following age groups: 148 cadets (males: age 8-12 years; females: 7-11 years), 155 children (males: age 13-14 years; females: 12-13 years), 243 juveniles (males: age 15-16 years; females: 14-15 years), 203 juniors (males: age 17-18 years; females: 16-17 years) and 259 seniors (males: 19 years and older; females: 18 years and older).

For the cadets, the weekly training sessions varied be- tween 2 and $6(\mathrm{M}=3.49 ; \mathrm{SD}=0.97)$; the number of hours per session varied between 1 and 3 hours $(M=1.68$; $\mathrm{SD}=0.60)$, corresponding to a weekly practice of approximately 6 hours.

For the children, the weekly training sessions varied between 2 and $8(\mathrm{M}=4.49 ; \mathrm{SD}=1.44)$; the number of hours per session varied between 1 and 3 hours $(\mathrm{M}=2.03 ; \mathrm{SD}=0.59)$, corresponding to a weekly practice of approximately 8 hours.

For the juyeniles, the weekly training sessions varied between 2 and $10(\mathrm{M}=5.26$; $\mathrm{SD}=1.76)$; the number of hours per session varied between 1 and 3 hours $(\mathrm{M}=2.05 ; \mathrm{SD}=0.57)$, corresponding to a weekly practice of approximately 10 hours.

For the juniors, the amount of weekly sessions varied between 2 and $11(\mathrm{M}=6.02 ; \mathrm{SD}=2.06)$; the number of hours per session varied between 1 and 3 hours $(\mathrm{M}=2.23 ; \mathrm{SD}=0.57)$, corresponding to a weekly practice of approximately 12 hours.

For the seniors, the weekly training sessions varied between 2 and $11(\mathrm{M}=6.04$; $\mathrm{SD}=1.72)$; the number of hours per session varied between 1 and 4 hours $(\mathrm{M}=2.00 ; \mathrm{SD}=0.57)$, corresponding to a weekly practice of approximately 12 hours.

\section{Instruments}

For the EFA, the Portuguese version of the QRA was used. In its original form, this questionnaire consisted of 32 items with a 3-point Likert Scale, ranging from 1 (not very important) to 3 (very important). In this study, however, a 5-point Likert Scale was used, ranging from 1 (strongly disagree) and 5 (strongly agree), since a scale with three levels of answers is too restrictive and it may not make it possible to discriminate between individuals, therefore, in this type of questionnaire it is more advised to use a 5 level scale, ${ }^{21}$ see the examples of EMI ${ }^{22}$ and IMAAD. ${ }^{23}$ For the CFA and SEM, a Portuguese version of the QRA was used which consisted of 21 items with a 5-point Likert scale, ranging from 1 (strongly disagree) and 5 (strongly agree). The items were grouped posteriorly into seven factors (with three items each) which reflected the different reasons for dropout in swimming.

To assess the intentions, we created three specific items (e.g., 'I have the intention to return to federated swimming practice next season, such as I practiced be- 
fore dropping out, same type, duration and intensity of training and competition') which were measured using a 5-point Likert scale, ranging from 1 (No, for sure) and 5 (Yes, for sure). These items were formulated according to Ajzen ${ }^{24}$ recommendations on how to measure intentions. Similar procedures have been used in other studies. ${ }^{5}$ In this sample, this factor showed good internal consistency (0.93) and convergent validity $(0.83)$, as well as good adjustment values $\left(\chi^{2}=3.78 ; \mathrm{df}=1 ; \mathrm{P}=0.05\right.$; $\mathrm{NNFI}=0.997 ; \mathrm{CFI}=0.999$; RMSEA $=0.053$-RMSEA IC $90 \%=0.000-0.113 ;$ SRMR $=0.009$ ).

\section{Procedures: translation of the questionnaire}

For the translation and adaptation of the instrument from the original English to Portuguese, we adopted the methodological procedures suggested by Vallerand.25 Instead of the translation/back translation technique proposed by Vallerand, ${ }^{25}$ we used the committee approach methodology, as suggested by Brislin. ${ }^{26}$ The translation and adaptation was developed through five stages: 1) preliminary translation; 2) first committee; 3 ) second committee (this stage was over only when all of the specialists reached agreement and their opinion was unanimous with respect to the item content); 4) pilot study; and 5) final review (only for syntax).

\section{Procedures: data collection}

The swimmers were identified from the FPN database, filtrated by license number, so as to ensure that they definitely had dropped out of competitive swimming. Afterwards, an e-mail was sent to the clubs to explain the study's aims and to request the contact information (e-mail or telephone) of the athletes and/or guardians in the case of minors. From the 200 clubs contacted, 104 answers were obtained (52\%), resulting in 1,695 athlete contacts.

For the EFA, 400 athletes and/or guardians were contacted between February and March 2015; we obtained 366 answers. For the CFA and SEM, the other 1329 athletes and/or guardians were contacted between June and October 2015, resulting in 1008 answers. All of the athletes and/or guardians were individually contacted by telephone to explain the purpose of the study and to request an e-mail to which to send the questionnaire. A different link was emailed to each individual, assuring that the questionnaire and letter of intention explaining the study's purpose was received only once, so as to preserve the principle of data confidentiality. All subjects gave their written informed consent before participation. The questionnaires were filled out through the survey monkey platform, with a mean filling out time of 12 minutes. Some studies have been using this platform. ${ }^{27}$

\section{Statistical analysis}

The analyses were realized with independent samples (one for EFA and other for the CFA and SEM). According to Kline, ${ }^{20}$ it is not appropriate to use the same data from the EFA to assess the quality of the models to be estimated with the CFA.

As for the EFA, a ratio of 10:1 (the number of individuals by item on the questionnaire) was advised for this kind of analysis 19 and recommendations by several authors 19, 20 were considered, namely the methods of the principal components with oblique rotation, Kaiser criteria (eigenvalue $\geq 1.0$ ), acceptable KaiserMeyer-Olkin (KMO $\geq 0.08, \mathrm{P} \leq 0.01)$, measure of sampling and Bartlett's test for sampling adequacy and sphericity, factor loadings $\geq 0.50$, variance explained by the factors $\geq 40 \%$ and internal consistency (Cronbach's alpha $\geq 0.70$ ) which should not increase if an item is eliminated and only factors with at least three items should be retained. The EFA was conducted using SPPS 20.0.

As for the CFA and SEM, a ratio of 15:1 (the number of subjects by the parameters to be estimated) was thought to be able to minimize the issue related to nonnormal data distribution ${ }^{19}$ because the normalized Mardia, ${ }^{28}$ coefficient indicated a multivariate non-normal distribution of the data both for the measurement model and the structural model (100.16 and 100.36), respectively.

The analysis was conducted following orientations of several authors 19,29 specifically, the estimation method of maximum likelihood (ML); chi-square $\left(\chi^{2}\right)$; respective degrees of freedom (df) and significance level $(\mathrm{P})$; indexes of quality of adjustment such as the standardized root mean square residual (SRMR), Comparative Fit Index (CFI), Non-Normed Fit Index (NNFI), root mean square error of approximation (RMSEA); and the respective confidence intervals $(90 \% \mathrm{CI})$. We adopted 
the cut-off values of $\mathrm{Hu}$ and Bentler: $30 \mathrm{SRMR} \leq 0.08$, CFI and NNFI $\geq 0.95$, and RMSEA $\leq 0.06$. Additionally, convergent validity was analysed by calculating the average variance extracted (AVE), considering values of $A V E \geq 0.50$. We also analyzed the discriminant validity; the value of the factors when above the square of the correlation between the same items; and the composite reliability (CR), considering the values of $C R \geq 0.70$ as cutting values. ${ }^{19}$ The analysis was undertaken using AMOS 20.0.

For the invariance analysis, we adopted the recommendations of several authors. ${ }^{29,31}$ The models showed acceptable values of adjustment in each of the gender groups as well as the configural, metric, scalar and residual invariance. According to Cheung and Rensvold, ${ }^{31}$ the invariance assumptions are verified by the differences of the CFI $(\triangle \mathrm{CFI} \leq 0.01)$. The analysis was undertaken using AMOS 20.0.

\section{Results}

From the EFA, seven factors (eigenvalue $\geq 1$ ) were extracted. These factors taken together justify $71.12 \%$ of the total variance seen in the result, which is satisfactory for these kinds studies. ${ }^{19}$ Eleven of the 32 items were eliminated $(3,4,9,13,19,20,22,28,30$ and 31) due to their factorial weight being less than 0.30 , which is not considered acceptable. ${ }^{20}$ The results of the commonalities were shown to be acceptable $(\geq 0.50)$, indicating that a good part of the variance in the results of each item is explained by the factorial solution found. ${ }^{19}$

In relation to the factorial weights and respective factors, the values fluctuate between 0.52 and 0.93 , which is considered excellent. ${ }^{20}$ The internal consistency of the factors were revealed to be adequate, according to the criteria adopted as part of the methodology, although three factors had a value of less than 0.70 but

TABLE I.-Exploratory Factor Analysis in Questionnaire of Reasons for Attrition in Swimming (QRA).

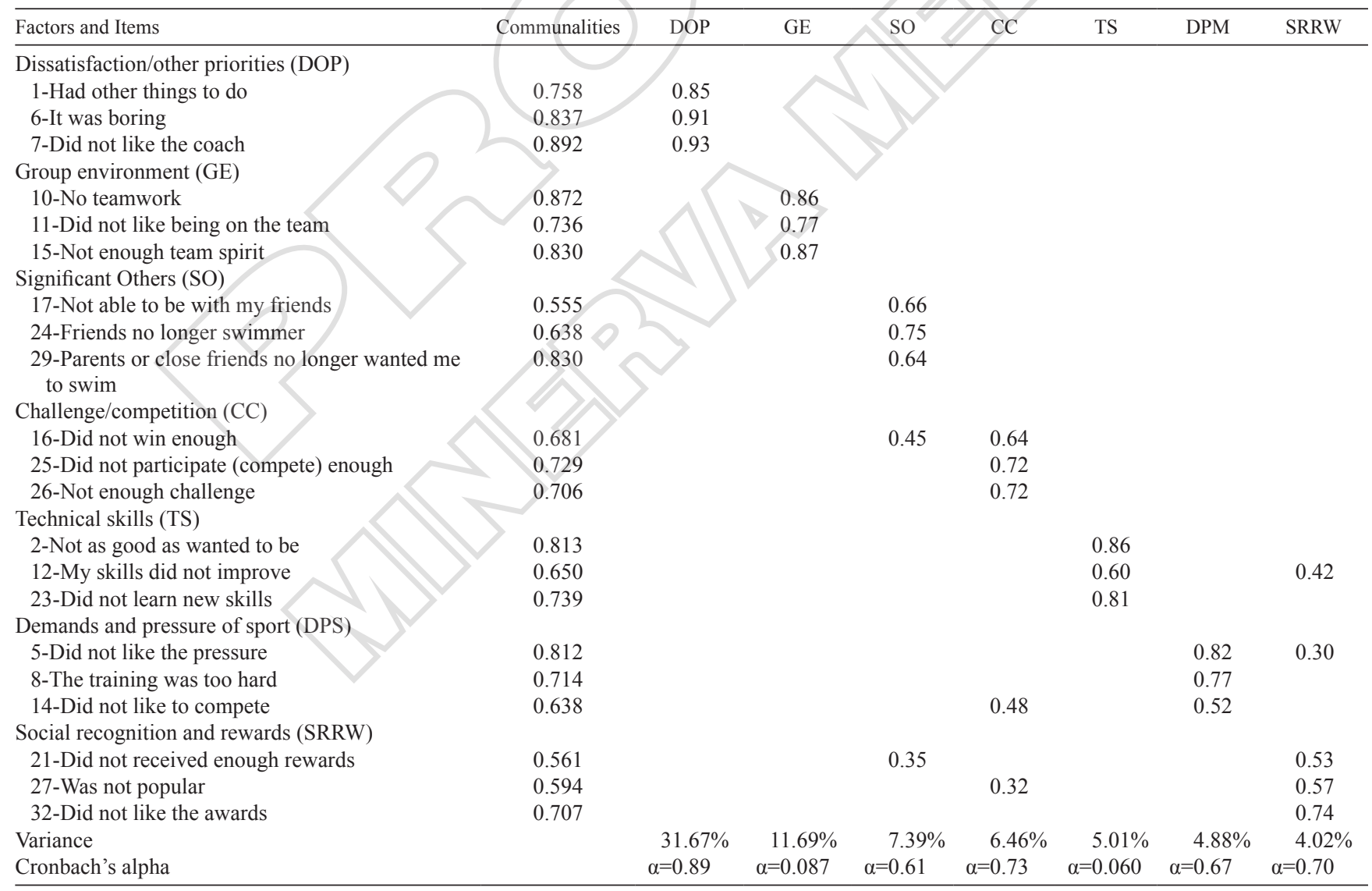


always greater than 0.60 , which can be considered an acceptable limit, ${ }^{19}$ especially when dealing with factors with few items. Furthermore, the internal consistency of the factors did not increase when deleting some of the items. Finally, as shown in Table I, the analysis of the semantic content of the items on each of the factors resulted in these designations: dissatisfaction/others priorities (DOP), group environment (GE), significant others (SO), challenge/competition (CC), technical skills (TS), demands and pressure of Sport (DPS) and social recognition/rewards (SRRW).

Regarding the CFA, positive correlations between all the factors were verified (0.10-0.92), with all being sig-

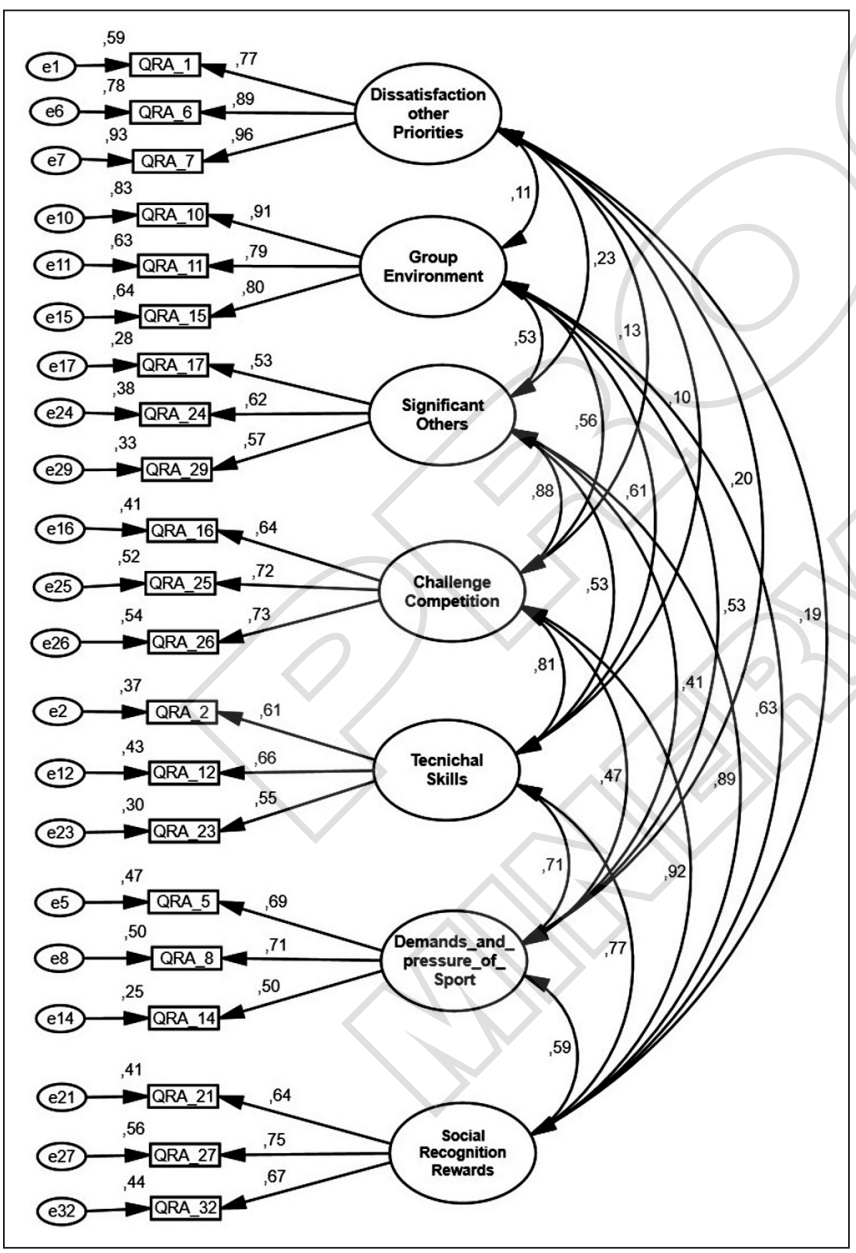

Figure 1.-Standardized individual parameters (covariance factors, factorial weights and measurement errors), all of which were significant in the Questionnaire of Reasons for Attrition in Swimming (QRA) (seven factors/21 items) for the Portuguese sample. nificant, with the exception of the correlations between the factors: DOP-GE (0.11) and DOP-TS (0.10.). The factorial validity was verified, as every item had a factorial weight on its respective factors $(\mathrm{P}<0.05)$ that varied between 0.50 and 0.96 , explaining at least $25 \%$ of the latent factor variance (Figure 1). 19

As shown in Table II, the measurement model presented good values of internal consistency, varying between 0.67 and 0.91 . Regarding convergent validity, some issues can be verified within the factors SO, CC, TS, DPS and SRRW, because the AVE values are lower than the ones adopted as part of the methodology $(\geq 0.50)$. Only the DOP and GE factors did not show convergent validity issues. When analysing the discriminant validity, the results revealed issues between the factors: SO-CC (0.77); SO-SRRW (0.79); CC-TS (0.66); CC-SRRW (0.85); TS-DPS (0.50) and TS-SRRW (0.59), as the square of the correlations between factors $\left(r^{2}\right)$ were above the AVE of both factors. ${ }^{19}$

As shown in Table III, the measurement model presented a reasonable adjustment to the data 19,29 although not all the cut-off values were accomplished as pointed in the methodology. ${ }^{30}$ The data also revealed that the model is invariant between genders, as indicated by the methodology. 31

The analysis of the predictive value between the reasons for dropout and the intention to return to the practice revealed that the model is suited to the data $\left(\chi^{2}=1000.64\right.$; $\mathrm{df}=222 ; \chi^{2} / \mathrm{df}=4.50 ; \mathrm{p}=0.001 ; \mathrm{NNFI}=0.918 ; \mathrm{CFI}=0.934$; RMSEA $=0.059 ; \quad$ RMSEA IC $90 \%=0.055-0.063$; $\mathrm{SRMR}=0.050$ ) by verifying that the factors DOP, GE, $\mathrm{CC}$ and DPS negatively predict the intention to return. Nevertheless, only with respect to the factors $\mathrm{CC}$ and DPS, are the values significant $(-0.48$ and -0.38$)$. The factors SO, TS and SRRW positively predict the intention to return, although only the values for factor SRRW were significant $(0.55$, Figure 2$)$.

\section{Discussion}

The main purpose of this study, which is to validate and to assess the psychometric qualities of the QRA, was achieved, since the results from the EFA show good initial psychometric properties for a model of seven factors with 21 items. Eleven items from the original QRA were deleted. Similar evidence was reported with respect to the Finnish version, ${ }^{16}$ as the authors of this 
TABLE II.-Internal reliability convergent and discriminant validity and average variance extracted.

\begin{tabular}{lccccccccc}
\hline Factors & CR & AVE & DOP & GE & SO & CC & TS & DPS & SRRW \\
\hline DOP & 0.91 & 0.77 & 1 & $0.01 *$ & $0.05^{*}$ & $0.01^{*}$ & $0.01^{*}$ & $0.04^{*}$ & $0.03^{*}$ \\
GE & 0.87 & 0.70 & - & 1 & $0.28^{*}$ & $0.31^{*}$ & $0.37^{*}$ & $0.28^{*}$ & $0.40^{*}$ \\
SO & 0.70 & 0.33 & - & - & 1 & $0.77^{*}$ & $0.28^{*}$ & $0.17^{*}$ & $0.79^{*}$ \\
CC & 0.74 & 0.49 & - & - & - & 1 & $0.66^{*}$ & $0.22^{*}$ & $0.85^{*}$ \\
TS & 0.75 & 0.37 & - & - & - & - & 1 & $0.50^{*}$ & $0.59^{*}$ \\
DPS & 0.67 & 0.41 & - & - & - & - & - & 1 & $0.35^{*}$ \\
SRRW & 0.72 & 0.47 & - & - & - & - & - & - \\
\hline
\end{tabular}

CR: composite reliability; AVE: average variance extracted; DOP: dissatisfaction/other priorities; GE: group environment; SO: significant others; CC: challenge/ competition; TS: technical skills; DPS: demands and pressure of sports; SRRW: social recognition/rewards. $* r^{2}$.

TABLE III.-Fit indices of measurement model of Questionnaire of Reasons for Attrition in Swimming (QRA) for the Portuguese sample and invariance of the measurement model of the QRA in the Portuguese sample for male and female.

\begin{tabular}{|c|c|c|c|c|c|c|c|c|c|c|}
\hline Model's & $\chi^{2}$ & $\Delta \chi^{2}$ & $\mathrm{df}$ & $\Delta \mathrm{df}$ & SRMR & NNFI & $\mathrm{CFI}$ & RMSEA & $\mathrm{CI}$ & $\Delta \mathrm{CFI}$ \\
\hline Model QRA & $927.5^{*}$ & - & 168 & - & 0.052 & 0.900 & 0.920 & 0.067 & $0.063-0.071$ & - \\
\hline Model QRA (Male) & $685.5^{*}$ & - & 168 & - & 0.060 & 0.895 & 0.903 & 0.076 & $0.070-0.082$ & - \\
\hline Model QRA(Female) & $570.3^{*}$ & - & 168 & - & 0.057 & 0.896 & 0.905 & 0.072 & $0.066-0.079$ & - \\
\hline CI & $1341.3^{*}$ & - & 336 & - & - & - & 0.908 & & - & - \\
\hline MI & $1381.8 *$ & 40.55 & 350 & 14 & - & - & 0.905 & & - & 0.003 \\
\hline SI & $1448.4^{*}$ & 107.16 & 378 & 42 & - & - & 0.901 & & - & 0.007 \\
\hline RI & $1610.1 *$ & 268.81 & 399 & 63 & - & - & 0.886 & & - & 0.022 \\
\hline
\end{tabular}

CI: configural invariance; MI: measurement Invariance; SI: scale invariance; RI: residual invariance; $\chi^{2}$ : chi-square; $\Delta \chi^{2}$ : differences in the value of chi-square; df: degrees of freedom; $\Delta$ df: differences in the degrees of freedom; SRMR: Standardized Root Mean Square Residual; NNFI: Non-normed Fit Index; CFI: Comparative Fit Index; RMSEA: Root Mean Squared Error of Approximation; CI: confidence interval; $\Delta$ CFI: differences in the value of the Comparative Fit Index; Model 1: Validation of QRA for the Portuguese sample (seven factors/21 items). $* \mathrm{P}<0.001$.

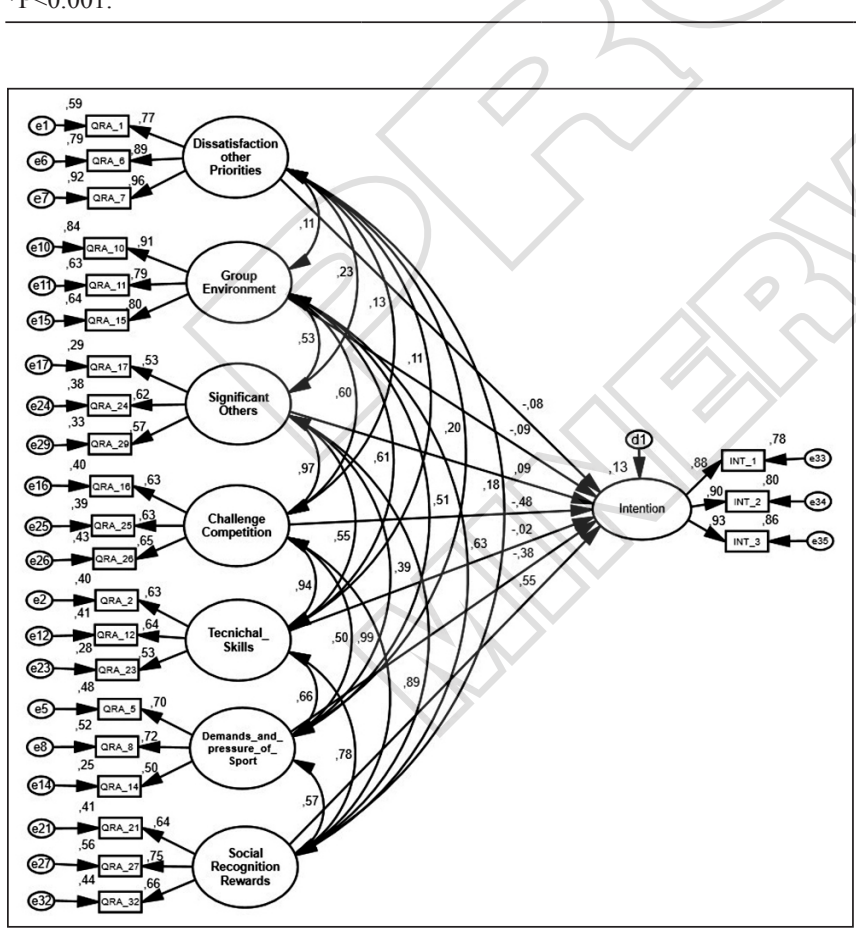

Figure 2.- Structural equation modeling between Questionnaire of Reasons for Attrition in Swimming (QRA) factors and intentions. version also reported having the eliminated 11 items from the questionnaire, although with a primary factorial structure of four factors (Social Issues, Ability Related, Extrinsic Motivation and Lack of Interests). This differs from the solution in the present study essentially because the Social Issues factor in the present study is divided into two factors (Group Environment and Social Recognition/Rewards).

On the other side, Rottenstein et al. ${ }^{16}$ deleted the items associated with our factor Challenge/Competition, and in our study, we eliminated the items associated with external reasons (e.g., "Not able to use the equipment or enough facilities", "Did not travel enough"), which correspond to the Extrinsic Motivation factor from the study of Rottenstein et al. ${ }^{16}$

In the present study, besides the fact that the eliminated items have factorial weights below 0.30 , there was some evidence that might require some attention, namely the existence of cross loadings on items 5,12 , $14,16,21$ and 27. Although their differences are greater than 0.15 , there are no doubts about which factor each item belongs, and the items ought to stay where they 
have the most factorial weight. ${ }^{20}$ The only exception is item 14 (Did not like to compete), which shows a factorial weight of 0.48 on the $\mathrm{CC}$ factor and 0.52 on the DPS factor, which can indicate this item should be eliminated. However, sharing the opinion of Kline, ${ }^{20}$ who advises some exercising prudence when eliminating items before the psychometric properties have been analysed with more robust techniques, we decided to keep item 14 in the DPS factor (Demands and Pressure of Sport).

The results from the CFA indicated reasonable adjustment values, although not all of the conservative cut-off values were reached ${ }^{30}$ mainly regarding the incremental rates (NNFI and CFI). However, some authors, ${ }^{29}$ in order to avoid the rejection of good models, suggest values adjusted on these coefficients $(\geq 0.90)$. Regarding reliability, all factors showed an adjusted internal consistency, with $\mathrm{CR}$ values between 0.67 and 0.91 .19 There is also verifiable factorial validity because all of the items have a factorial weight on the respective factor $(\mathrm{P}<0.05)$, fluctuating between 0.50 and 0.96 and explaining at least $25 \%$ of the latent factor variance. 19

On the other hand, there are some issues regarding the convergent validity of the factors SO, CC, TS, DPS and SRRW, that is, the items are not strongly associated with these factors, although, the factorial weights are greater than 0.50 and statistically significant within the respective factors, which according to Hair et al. ${ }^{19}$ is an indicator of suitable convergent validity. Also, neither of these items showed cross-loadings, nor very high residual values, being an adjustment indicator of the items on those factors. ${ }^{29}$

Regarding discriminant validity, some factors showed issues, namely SO-CC, SO-SRRW, CC-TS, CC-SRRW, TS-DPS and TS-SRRW, that is, the factors are not distinguishable enough from each other. ${ }^{19}$ This was, in a way, expected because the questionnaire lacks a theoretical support model and the factors show high correlations between them (Figure 1). This seems to confirm the opinion of several authors, $2,8,9$ that practice dropout does not occur from an isolated reason but from a set of more or less diversified reasons (personal or situational, controlled or not controlled by the subject), as suggested by the integrative model developed by Gould. ${ }^{2}$ With respect to model invariance, the results support the measure equivalence between the two samples, therefore, they are conceptualized the same way between genders, notwithstanding the fact that on the residual invariance the assumptions adopted in the methodology were not fulfilled. This fact, however, is not an indicator of lack of invariance of the model; there are some authors that consider it less common to analyse this criterion because it is quite restrictive. ${ }^{29}$

Taking into account the analysis of the predictive reasons in relation to the athletes' intentions to return to the practice, the structural model showed that factors CC and DPS negatively predict the athletes' intention to return to the practice. This means, when the athlete's dropout is for reasons such as "Not enough challenge" or "Did not like the pressure", they appear not to have future intentions of returning to swimming practice, at least for the following season. Still, the SRRW factor predicts positively the athletes' intention to return to practice the following season when they drop out of it for reasons such as "did not like the awards". This question is important from a behavioural perspective, as Ajzen, ${ }^{12}$ the author of the theory of planned behaviour, has said that intentions are the best predictors of behaviour.

\section{Conclusions}

In brief, these results represent an important step to understanding dropout in swimming due to the factorial solution of the QRA founded in this study showed, acceptable psychometric properties. This enables researchers to have a valid and reliable instrument to assess the reasons behind people of both genders dropping out of sports, including evidence of the predictive value of the behavioural intention to return to the practice. This, in turn, makes it possible to identify the primary areas where actions can be taken so that this phenomenon can be prevented.

\section{STUDY 2}

Organized sports play an important role in the development of children and youngsters. ${ }^{1}$ Children and youngsters prematurely dropping out, however, is happening more often in several sports. ${ }^{11}$ It is estimated that more than one-third of all participants, ages 10-17, drop out of their sports practice annually, a significant percentage that represents several million youngsters across Europe and North America. ${ }^{32}$ According to 
Amorose and Weiss, ${ }^{32}$ the youngsters' call to dropout or maintain practice seems to be influenced by several reasons, including interests conflicting, other priorities, lack of success or improvement, disliking the coach and amusement. Notwithstanding, it seems that dropout phenomenon studies somehow are still not greatly developed, ${ }^{4}$ and the swimming context is not an exception. ${ }^{11}$

Very recently, the Olympic Committee of Portugal ${ }^{33}$ issued an alert about this problem, highlighting that "the numbers of affiliated athletes on sport federation do not show signs of significant increase and there are several sports that are facing a regressive tendency, compared with the numbers reached during previous decades". This assumes that the theme is current and relevant. It is expected that the present study can aid sport leaders, coaches and athletes in preventing practice dropout, offering useful guidelines both for the training process and decisions with respect to sports politics to be implemented with the plan to decrease the dropout.

\section{Subjects}

\section{Materials and methods}

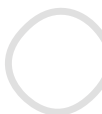

This study included 1008 former swimmers (543 male, 465 female; mean age 16.26, SD 6.12) who dropped out of competitive swimming practice during the 2012-2013 and 2013-2014 seasons and did not return. This sample comprised the following age groups: 148 cadets (males: age 8-12 years; females: 7-11 years), 155 children (males: age 13-14 years; females: 12-13 years), 243 juveniles (males: age 15-16 years; females: 14-15 years), 203 juniors (males: age 17-18 years; females: 16-17 years) and 259 seniors (males: 19 years and older; females: 18 years and old).

For the cadets, the weekly training sessions varied between 2 and $6(\mathrm{M}=3.49 ; \mathrm{SD}=0.97)$; the number of hours per session varied between 1 and 3 hours $(M=1.68$; $\mathrm{SD}=0.60$ ), corresponding to a weekly practice of approximately 6 hours.

For the children, the weekly training sessions varied between 2 and $8(\mathrm{M}=4.49 ; \mathrm{SD}=1.44)$; the number of hours per session varied between 1 and 3 hours $(\mathrm{M}=2.03 ; \mathrm{SD}=0.59)$, corresponding to a weekly practice of approximately 8 hours.

For the juveniles, the weekly training sessions varied between 2 and $10(\mathrm{M}=5.26$; $\mathrm{SD}=1.76)$; the num- ber of hours per session varied between 1 and 3 hours $(\mathrm{M}=2.05 ; \mathrm{SD}=0.57)$, corresponding to a weekly practice of approximately 10 hours.

For the juniors, the amount of weekly sessions varied between 2 and $11(\mathrm{M}=6.02 ; \mathrm{SD}=2.06)$; the number of hours per session varied between 1 and 3 hours $(\mathrm{M}=2.23 ; \mathrm{SD}=0.57)$, corresponding to a weekly practice of approximately 12 hours.

For the seniors, the weekly training sessions varied between 2 and $11(\mathrm{M}=6.04 ; \mathrm{SD}=1.72)$; the number of hours per session varied between 1 and 4 hours $(\mathrm{M}=2.00, \mathrm{SD}=0.57)$, corresponding to a weekly practice of approximately 12 hours.

\section{Instruments}

For this study we used the Portuguese version of the QRA that was validated in Study 1. It consisted of 21 items scored using a 5-point Likert Scale, ranging from 1 (strongly disagree) to 5 (strongly agree). The items were grouped posteriorly into seven factors (with three items each) which reflect the different reasons for dropout in swimming.

\section{Procedures: data collection}

The swimmers were identified through the FPN database, filtered by their license number, so as to guarantee that they definitely had dropped out from competitive swimming practice. We then sent to their clubs an email and letter explaining the study's objectives and requesting contact information (e-mail or telephone) for the athletes and/or their respective guardians. From the 200 clubs contacted, 104 answers (52\%) were obtained, resulting in 1695 athlete contacts. We received answers from 1008 athletes and/or guardians from the 1695 that we contacted between February and October 2015. All of the athletes and/or guardians were contacted individually by telephone, informed aims of the study and asked for an e-mail to which we could send the questionnaire. A different link for each individual was emailed, assuring that the questionnaire and letter of intention was received only once, which preserved the principle of data confidentiality. All subjects gave their written informed consent before participation. The questionnaires were filled out through the survey monkey platform, with a mean filling out time of 10 minutes. 


\section{Statistical analysis}

We first conducted a univariate analysis of location measures and central tendency (mean) and dispersion measures (standard deviation). Secondly, we used an independent sample $t$-test (comparison of means between two groups) to analyse the differences between genders and one-way Analysis of Variance (ANOVA), a comparison of means on more than two groups (age groups). The ANOVA was complemented with the Tukey post-hoc test, with the exception of the DPS factor due to the variances not being homogeneous (Levene's Test $=0.03$ ), because of that we used the Games-Howell Test. ${ }^{34}$ The significance level adopted to reject the null hypothesis was $\mathrm{P} \leq 0.05$. The analysis was undertaken using the SPSS 20.0.

\section{Results}

As shown in Table IV, the most significant reasons for dropout in this sample were

associated with the DOP (e.g., "Had other things to do"), TS (e.g., "My skill did not improve") and DPS (e.g., "Did not like the pressure") factors, and the less valuable ones were associated with the GE (e.g., "No team work"), CC (e.g., "Did not win enough"), SO (e.g., "Parents or close friends no longer wanted me to swim") and SRRW (e.g., "Did not received enough rewards") factors. The results showed that both genders value the same factors similarly, with the exception of the DOP and DPS factors, which were more valued by the men and women, respectively; these differences were statistically significant $\left(\mathrm{t}_{\mathrm{DOP}=} 2.05, \mathrm{P}=0.042\right.$ and $\left.\mathrm{t}_{\mathrm{DPS}}=-3.73, \mathrm{P}=0.001\right)$. For the male participants the reasons associated with DOP were more important or valued than for the female athletes, while on the other hand, for the female participants the reasons associated with DPS were more important or valued than for the male athletes.

Regarding the competitive rankings, the DOP factor was revealed to be more valued by seniors, the TS and DPS factors by cadets and children, the CC and SRRW factors by cadets, the SO factor by juveniles and juniors, and the GE factor by juniors. The one-way ANOVA revealed the following significant differences: (F $[\mathrm{DOP}]=3.17 ; \mathrm{P}=0.013),(\mathrm{F}[\mathrm{GE}]=4.98 ; \mathrm{P}=0.001)$, $(\mathrm{F}[\mathrm{SO}]=4.23 ; \mathrm{P}=0.002),(\mathrm{F}[\mathrm{CC}]=2.77 ; \mathrm{P}=0.026),(\mathrm{F}$ $[\mathrm{TS}]=[3.31] ; \mathrm{P}=0.010),(\mathrm{F}[\mathrm{DPS}]=26.95 ; \mathrm{P}=0.000)$ and ( $\mathrm{F}[\mathrm{SRRW}]=2.87 ; \mathrm{P}=0.022)$. On the Tukey post-hoc and Games-Howell tests, however, the results show differences on the DOP factor for cadets and seniors $(\mathrm{P}=0.038)$ and for juveniles and seniors $(\mathrm{P}=0.033)$. On the TS factor, differences occurred between children and seniors $(\mathrm{P}=0.033)$ and on the DPS factor there were significant statistical differences among the younger age groups (cadets and children) and the remaining age groups (juveniles, juniors and seniors) (all $\mathrm{P}<0.001)$. For the GE factor there were differences between cadets and seniors $(\mathrm{P}=0.031)$, between children and seniors $(\mathrm{P}=0.027)$ and between juniors and seniors $(\mathrm{P}=0.001)$. For the $\mathrm{CC}$ and SRRW factors, there were verifiable differences between cadets and juveniles $(\mathrm{P}=0.034$ and $\mathrm{P}=0.44$, respectively), and on the SO factor there were differences between juveniles and juniors, and between juveniles and seniors $(\mathrm{P}=0.014$ and $\mathrm{P}=0.016)$ respectively.

\section{Discussion}

The results of Study 2 show that the following factors were more significant for practice dropout: DOP (e.g.,

TABLE IV.-Means and Standard Deviations of Questionnaire of Reasons for Attrition in Swimming (QRA) factors, gender and competitive ranking.

\begin{tabular}{|c|c|c|c|c|c|c|c|c|}
\hline Factors & $\begin{array}{l}\text { Most significant } \\
\text { factor }\end{array}$ & $\begin{array}{l}\text { Male } \\
\mathrm{M} \pm \mathrm{SD}\end{array}$ & $\begin{array}{l}\text { Female } \\
\mathrm{M} \pm \mathrm{SD}\end{array}$ & $\begin{array}{l}\text { Cadets } \\
\mathrm{M} \pm \mathrm{SD}\end{array}$ & $\begin{array}{c}\text { Children } \\
\mathrm{M} \pm \mathrm{SD}\end{array}$ & $\begin{array}{c}\text { Juveniles } \\
\mathrm{M} \pm \mathrm{SD}\end{array}$ & $\begin{array}{l}\text { Juniors } \\
\mathrm{M} \pm \mathrm{SD}\end{array}$ & $\begin{array}{l}\text { Seniors } \\
\mathrm{M} \pm \mathrm{SD}\end{array}$ \\
\hline DOP & $3.05 \pm 1.38$ & $3.13 \pm 1.36$ & $2.95 \pm 1.39$ & $2.89 \pm 1.38$ & $2.93 \pm 1.46$ & $2.94 \pm 1.38$ & $3.09 \pm 1.34$ & $3.29 \pm 1.32$ \\
\hline $\mathrm{TS}$ & $2.16 \pm 0.98$ & $2.15 \pm 0.99$ & $2.16 \pm 0.97$ & $2.29 \pm 1.12$ & $2.30 \pm 1.04$ & $2.10 \pm 0.93$ & $2.19 \pm 0.97$ & $2.00 \pm 0.91$ \\
\hline DPS & $2.10 \pm 1.01$ & $1.99 \pm 0.97$ & $2.21 \pm 1.03$ & $2.48 \pm 1.15$ & $2.56 \pm 1.05$ & $2.05 \pm 1.00$ & $2.02 \pm 0.88$ & $1.69 \pm 0.79$ \\
\hline GE & $1.92 \pm 1.15$ & $1.87 \pm 1.12$ & $1.99 \pm 1.19$ & $2.04 \pm 1.22$ & $2.06 \pm 1.29$ & $1.84 \pm 1.31$ & $2.11 \pm 1.23$ & $1.70 \pm 0.92$ \\
\hline $\mathrm{CC}$ & $1.73 \pm 1.15$ & $1.70 \pm 0.91$ & $1.76 \pm 0.91$ & $1.87 \pm 1.01$ & $1.70 \pm 0.83$ & $1.58 \pm 0.84$ & $1.77 \pm 0.96$ & $1.78 \pm 0.90$ \\
\hline SO & $1.68 \pm 0.79$ & $1.66 \pm 0.80$ & $1.70 \pm 0.78$ & $1.65 \pm 0.85$ & $1.58 \pm 0.70$ & $1.77 \pm 0.78$ & $1.80 \pm 0.87$ & $1.56 \pm 0.73$ \\
\hline SRRW & $1.50 \pm 0.73$ & $1.52 \pm 0.77$ & $1.47 \pm 0.70$ & $1.62 \pm 0.89$ & $1.45 \pm 0.68$ & $1.39 \pm 0.61$ & $1.55 \pm 0.79$ & $1.53 \pm 0.72$ \\
\hline
\end{tabular}

M: mean; SD: standard deviation; DOP: dissatisfaction/other priorities; TS: technical skills; DMS: demands and pressure of sport; GE: group environment; CC: challenge competition; SO: significant others; SRRW: social recognition rewards. 
"Had other things to do"), TS (e.g., "My skill did not improve") and DPS (e.g., "Did not like the pressure"). This corroborates results from several studies in the past decades. ${ }^{2}, 11,15,35,36$ On the other hand, the following factors were the least significant reasons for practice dropout: GE (e.g., "No team work"), SO (e.g., "Not able to be with my friends") and SRRW (e.g., "Was not popular"), these results were similar to what has been was reported in some others studies. ${ }^{3,36}$

The differences found between genders on the DPS factor, with it being more valued by the female athletes, also are in accordance with some previous studies. ${ }^{3,36}$ It seems that demand and pressure by the sport are associated with weak perception of competence among female participants ${ }^{37}$ as evidenced by some other studies. ${ }^{38}$ On the other hand, for the DOP factor, the results pointed to this factor having greater significance among male athletes than female athletes. Although the general literature has pointed out these reasons as the main causes for dropout, ${ }^{2,32}$ as it also happens, in the current study, up until now it looks like no research had ever reported differences with respect to this factor (or the items that set it) in relation to gender, since it always shows up as being associated with dropout, no matter the gender or sport practiced. ${ }^{39}$ However, since the present study was specifically done with swimming athletes, this sample's specificity was probably a determinant factor in these differences.

Regarding the different age groups, the results showed significant differences in all factors, providing evidence that the reasons for dropout have more or less relevance according to the different age groups in question, a fact that has been highlighted by Weinberg and Gould. ${ }^{39}$ Namely, the results showed that senior swimmers gave more significance to the DOP factor (e.g., "Had other things to do") regarding dropout. It seems there is no support for this statement in the literature, but most of the studies were made with groups of athletes age 10-18.11 In fact, according to Stambulova, 40 this evidence seems to be related to different modifications which usually occur during this age group (scholastic, familiar and professional context), as well as the apparent sameness related to lack of enjoyment during training and the over-emphasis on results and victory. ${ }^{32}$ Besides that, in the Portuguese context, this fact could also be related to the years that swimmers go through with the same coach, creating a disruption in the athletecoach relationship.
The GE factor (e.g., "Not enough team spirit") was the most significant factor among the cadets, children and juveniles, which shows that these age groups attached a great deal of importance to this factor as a determinant for dropout. Similar results were found in studies, ${ }^{1,3}$ where the authors pointed to the importance of the group environment, mainly in relation to the younger levels. This conclusion was recently fortified by Rottenstein et al. ${ }^{16}$ who highlighted that is important that coaches actively promote team-building and facilitate group dynamics exercises, as well as create a motivational and thrilling environment for young athletes.

The SO factor (e.g., "Parents or close friends no longer wanted me to swim") was the most significant factor among juveniles and juniors, revealing the importance that significant others (in this specific case this factor represented parents and friends) have on dropout. As several authors 16,41 have pointed out, parents and/or friends can have a negative influence on young athletes and in the structured sports context it is important that parents and/or significant others are integrated into the process of formation and competition throughout the young athletes' career.

The CC (e.g., "Did not win enough") and SRRW (e.g., "Did not received enough rewards") factors were the most significant among the cadets. The importance that this age group attributes to these factors has also been demonstrated by other studies. ${ }^{3,} 35$ This shows it is important to create a competitive environment that is less focused on results so that children can evolve and learn, through sports, important competences for life (cooperation, fair-play, self-control), without there being much a lot of emphasis on results and victory and consequently social recognition and awards. ${ }^{42}$

With respect to the TS factor (e.g., "Did not learn new skills") there was a greater importance attributed to this factor among the children, which corroborates results from a study by Petlichkoff. ${ }^{35}$ This situation seems to be associated with the fact that for this age group this is a time of learning and developing specific techniques. ${ }^{32}$

Finally, the DPS factor (e.g., "Did not like to compete") was of greater importance to the cadets and children, showing that the pressures and demands associated with swimming are of greater importance for younger age groups than for the older age groups. Similar evidence was found by Butcher et al. ${ }^{43}$ Therefore, it is important to create an environment that favours 
personal development and learning, avoiding premature specialization, which is something that happens over and over. ${ }^{44}$ Sports' practice should support the development stages, as is recommended by the development model of sports participation, ${ }^{44}$ which may provide a greater feelings of autonomy, competence and relatedness and greater autonomous motivation. 45

\section{Conclusions}

The results of this study can be used as a relevant tool to understand the sports dropout, specifically in swimming, as it contributes to filling an existing gap in the literature by validating an instrument that assesses the dropout reasons after an athlete has dropped out of a sport. The paper also confirms the instruments' psychometric robustness and equivalence between genders, analyses the impact that the main reasons can have on the athletes' intention to return to the practice and identifies primary areas of action to prevent dropout. On the other hand, at the production level of knowledge on this issue, we think this makes a major contribution to the identification of the main reasons for Portuguese swimmers dropping out of the sport, providing evidence concerning the existent differences between genders and age groups. This will help to create the possibility of tools being developed to prevent this phenomenon, both with respect to training processes and decisions in sport politics. The results can aid coaches and leaders to understand how certain variables work (e.g., "Demand and pressure of the sport"), enabling them to adapt their interventions to the needs and constraints of each group, as well as helping the athletes themselves, enabling them to extend their sporting career, since the dropout from organized sports practice is increasing.

In short, the results shown in the present study lead to the following conclusions for practice: 1) promoting the fun side, especially in the young age groups, is important; 2) linking the training plan to all the other daily activities of the swimmer, involving the swimmer and significant others, especially those who most support the practice; 3 ) consider the inclusion of meetings in the schedule that can enrich the leisure/recreational component, suggesting its organization in each regional association; 4) pay special attention during times of change, mainly during school transitions, as there is a huge conflict concerning sports practice during that stage; 5) focus the training session plans on the tasks (self-referenced criteria) and not so much on the results, giving the athlete autonomy (guided discovery), so that he or she has a perception of his or her competence in a competition context and feel the pleasure of swimming practice; 6) value self-evolution (overcome oneself) before results; 7) the coach should pay attention to all, without exception, regardless of the physical and technical qualities that the swimmers might have. The athletes must feel that the coach is a reference and have to look at him as someone who is there to support them; 8) define balanced objectives, mainly focusing on tasks and giving less importance to the results. That means achievable and realistic results that should be defined according to the athlete and not according to parents or coaches.

As a consequence of the present study, some measures have already been implemented to reduce the dropout in swimming, in the strategic plan of the FPN, ${ }^{46}$ namely: 1) changes in the competitive schedule, with modifications in the competition typology, namely in the young age groups; 2) the implementation of an education plan for coaches not only on coaches' initial education stages but also during their careers with continuous education programs, with updated contents based on the data of the current study; 3) implementation of institutional measures to support the reconciliation of the sportive, academic and social aspects of life.

\section{References}

1. Fraser-Thomas J, Côte J, Deakin J. Understanding dropout and prolonged engagement in adolescent competitive sport. Psychol Sport Exerc 2008;9:645-62.

2. Gould D. Understanding attrition in children's sport. In: Gould D, Weiss M, editors. Advances in pediatric sport sciences: behavioral issues. Champaign, IL: Human Kinetics; 1987. p. 61-85.

3. Gould D, Feltz D, Horn T, Weiss M. Reasons for attrition in competitive youth swimming. J Sport Behav 1982;5:155-65.

4. Guillet E, Sarrazin P, Cury F. L'abandon sportif: de l'approache descriptive aux modèles interactionnistes. Science Motricité 2000;41:47-60

5. Guzmán J, Kingston K. Prospective study of sport dropout:A motivational analysis as a function of age and gender. Eur J Sport Sci 2012;12:431-42.

6. Quested E, Ntoumanis N, Viladrich C, Haug E, Ommundsen Y, Van Hoye A, et al. Intentions to drop out of youth soccer: a test of the basic needs theory among European youth in five countries. Int J Sport Exerc Psychol 2013;11:395-407.

7. Sarrazin P, Vallerand R, Guillet E, Pelletier L, Cury F. Motivation and dropout in female handballers:A 21-month prospective study. Eur J Soc Psychol 2002;32:395-8

8. Cervelló E, Escartí A, Gúzman J. Youth sport dropout from the achievement goal theory. Psicothema 2007;19:65-71. 
9. Sarrazin P, Guiilet E. Why they are not re-written? Variables and processes of sport dropout. In:Cury F, Sarrazin P, editors. Theories de la motivation et practiques sportives: état des recherches. Paris:Presses Universitaries de France; 2001. p. 223-54.

10. Cervelló E. Dropout in sport: proposals to improve grip in sports practice. In: Dósil J, editor. Psychology and sports performance. Spain: Ediciones Gersam; 2002. p. 175-88.

11. Crane J, Temple V. A systematic review of dropout from organized sport among children and youth. Eur Phys Educ Rev 2015;2:1-18.

12. Ajzen I. From intentions to actions: a theory of planned behaviour. In Kuhl J, Beckam J, editors. Action control from cognitions to behaviour. New York: Springer Publishers; 1985. p. 11-39.

13. Marrero G, Martín-Albo L, Núñez J. Cuestionario de motivos de inicio, mantenimiento, cambio y abandono de la actividad deportiva (MIMCA). In: Guillén F, editor. La psicología del deporte en España al final del milénio. Spain: Universidad de Las Palmas de Gran Canaria; 1999. p. 255-9.

14. Cecic-Erpic S. Elite sports career transition and prediction of the adaptation to the post-sports life (Unpublished doctoral dissertation). 2000. University of Ljubljana, Ljubljana, Slovenia.

15. Molinero O, Salguero A, Tuero C, Álvarez E, Márquez S. Dropout reasons in young Spanish athletes: relationship to gender, type of sport and level of competition. J Sport Behav 2006;29:255-69.

16. Rottenstein C, Laasko L, Pihalaja T, Kontinne N. Personal reasons for withdrawal from team sports and the influence of significant others among youth athletes. Int J Sports Sci Coach 2013;8:19-31.

17. Gill D, Gross J, Huddleston S. Participation motivation in youth sports. In:Roberts G, Landers D, editors. Psychology of motor behavior and sport. Champaign, IL: Human Kinetics; 1981. p. 3-29.

18. Salguero A, Tuero C, Márquez S. Adaptacion espanhola del Cuestionario de Causas de Abandono en la Práctica Deportiva:Validación y diferencias de género en jóvenes nadadores. Efdeportes 2003;8:56.

19. Hair J, Black W, Babin B, Anderson R. Multivariate data analysis New Jersey: Pearson Educational, Inc. Publishers; 2014

20. Kline R. Principles and practice of structural equation modelling. New York: The Guilford Press; 2011.

21. Hill M, Hill A. Investigação por Questionário. Lisboa: Edições Sílabo; 2000.

22. Markland D, Ingledew DK. The measurement of exercise motives: Factorial validity and invariance across gender of a revised Exercise Motivations Inventory. Brit J Health Psych 1997;2:361-76.

23. Fernandes HM. Análise fatorial confirmatória do IMAAD numa população adulta. Psychologica 2005;38:307-20.

24. Ajzen I. Constructing a TPB Questionnaire: conceptual and methodological considerations 2006 [Internet]. Available from: www.people. umass.edu/aizen/tpb.html [cited 2017, Jul 20].

25. Vallerand R. Vers une méthodologie de validation trans-culturelle de questionnaires psychologiques:Implications pour la recherche en langue française. Can Psychol 1989;30:662-80.

26. Brislin R. Translation and content analysis for oral and written material. In Triandis H, Berry J, editors. Handbook of Cross-Cultural Psychology. Needham Heights: Allyn and Bacon; 1980. p. 389-44.

27. Marques AI, Santos L, Soares P, Santos R, Oliveira-Tavares A, Mota $\mathrm{J}$, et al. A proposed adaptation of the European Foundation for Quality Management Excellence Model to physical activity programmes for the elderly - development of a quality self-assessment tool using a modified Delphi process. Int J Behav Nutr Phys 2011;8:104.

28. Mardia K. Measures of multivariate Skewness and Kurtosis. Biometrika 1970;57:519-30.

29. Byrne B. Structural equation modeling with AMOS: basic concepts, applications, and programming. New Jersey: Lawrence Erlbaum Associates Publishers; 2010.

30. Hu L, Bentler P. Cut-off criteria for fit indexes in covariance structure analysis:Conventional criteria versus new alternatives. Struct Equ Modeling 1999;6:1-55.

31. Cheung G, Rensvold R. Evaluating goodness-of-fit indexes for testing measurement invariance. Struct Equ Modeling 2002;9:233-55.

32. Weiss M, Amorose A. Motivational orientations and sport behaviour. In: Horn T editor. Advances in Sport Psychology. Champaing, IL: Human Kinetics; 2008. p. 115-56.

33. Comité Olímpico de Portugal. Valorizar e afirmar socialmente o desporto: um desígnio nacional 2015 [Internet]. Available from: http:// comiteolimpicoportugal.pt/ [cited 2017, Jul 20].

34. Ho R. Handbook of univariate and multivariate data analysis with IBM SPSS. New York: CRC Press; 2014.

35. Petlichkoff L. Group differences on achievement goal orientations, perceived ability, and level of satisfaction during an athletic season. Pediatr Exerc Sci 1993;5:12-24

36. Salguero A, Gonzalez-Boto C Tuero C, Márquez S. Identification of dropout reasons in young competitive swimmers. J Sports Med Phys Fitness 2003;43:524-30

37. Harter S. A new self-report scale of intrinsic versus extrinsic orientation in the classroom:Motivational and informational components. Dev Psychol 1981;17:300-12.

38. Guillet E, Sarrazin P, Fontayne P, Brustad R. Understanding female sport attrition in a stereotypical male sport within the framework of Eccles's expectancy-value model. Psychol Women Quart 2006;30:358-68.

39. Weinberg R, Gould D. Foundations of sport and exercise psychology. Champaign, IL: Human Kinetics; 2015.

40. Stambulova, N. Developmental sport career investigations in Russia:A post perestroika analysis. Sport Psychol 1994;8:221-37.

41. Fraser-Thomas J, Côte J. Understanding adolescents' positive and negative developmental experiences in sport. Sport Psychol 2009;23:3-23.

42. Fraser-Thomas J, Côte J, Deakin J. Youth sport programs: an avenue to foster positive youth development. Phys Educ Sport Pedagog 2005;10:19-40.

43. Butcher J, Lindner KJ, Johns DP. Withdrawal from competitive youth sport: a retrospective ten-year study. J Sport Behav 2002;25:145.

44. Côté J, Hay J. Children's involvement in sport: a developmental perspective. In:Silva J, Stevens D, editors. Psychological foundations of sport. Boston: Benjamin Cummings Publishers; 2002. p. 484-02.

45. Deci E, Ryan R. Self-determination theory: a macrotheory of human motivation, development, and health. Can Psychol 2008;49:182-5.

46. Silva A, Marinho D, Machado J, Campaniço J, Gil H, Costa M, et al. Política Desportiva FPN- Natação Pura. Portugal: Federação Portuguesa de Natação, editors [Internet] Available from: http://www. fpnatacao.pt/sites/default/files/imce/pdfs/1617/livro-politica_desportiva_1_0.pdf [cited 2017, Jul 20].

Conflicts of interest.- The authors certify that there is no conflict of interest with any financial organization regarding the material discussed in the manuscript. Acknowledgments.-The authors would like to thank all the swimmers and parents who participated in this study and the Portuguese Swimming Federation for supporting this study.

This research was awarded by COP/Millenium BCP Sport Sciences 2016.

Article first published online: April 26, 2017. - Manuscript accepted: April 11, 2017. - Manuscript revised: March 2, 2017. - Manuscript received: July 22, 2016. 